\title{
Kinetic and Modeling Studies of the Reaction of Hydroxyl Radicals with Tetrachloroethylene
}

\author{
LeAnn B. Tichenor, John L. Graham, Takahiro Yamada, and Philip H. Taylor* \\ Environmental Science and Engineering, University of Dayton Research Institute, 300 College Park, \\ Dayton, Ohio 43469-0132
}

\author{
Jingping Peng, Xiaohua Hu, and Paul Marshall \\ Department of Chemistry, University of North Texas, P.O. Box 305070, Denton, Texas 76203-5070
}

Received: September 10, 1999; In Final Form: December 21, 1999

\begin{abstract}
Rate coefficients are reported for the gas-phase reaction of the hydroxyl radical $(\mathrm{OH})$ with $\mathrm{C}_{2} \mathrm{Cl}_{4}\left(k_{1}\right)$ over an extended temperature range at $740 \pm 10$ Torr in a He bath gas. These absolute rate measurements were conducted using a laser photolysis/laser-induced fluorescence (LP/LIF) technique under slow flow conditions. The lower temperature values for $k_{1}$ are within $\pm 2 \sigma$ of previous data using different techniques. The overall slope of our Arrhenius plot varies slightly from previously reported values. Agreement within our own data holds up to $\sim 720 \mathrm{~K}$, but reliable measurement beyond this temperature was hampered by apparent thermal decomposition of our $\mathrm{OH}$ source (HONO). An Arrhenius fit to the data yielded the expression $k_{1}(T)=(1.68$ $\pm 0.25) \times 10^{-12} \exp (-764.2 \pm 79.1 / T)$, whereas a three-parameter Arrhenius fit yielded the expression $k_{1}(T)$ $=(1.93 \pm 0.20) \times 10^{-22}(T)^{3.2} \exp (660.8 \pm 54.6 / T)$, where $k$ is in units of $\mathrm{cm}^{3}$ molecule $\mathrm{s}^{-1}$. This work shows some deviation from previous low-temperature data. We propose that surface absorption influenced previously measured rate constants. Significant absorption was evident at low temperatures, and an experimental technique was developed to negate this effect. The predicted mechanisms were conceptualized using ab initio calculations to define the activated complex and transient intermediates, and thus predict the most likely path and products. Quantum RRK analysis yielded no overall pressure dependence. Model predictions indicate that trichloroethenol formation via $\mathrm{Cl}$ elimination dominates up to temperatures of $2000 \mathrm{~K}$. At flame temperatures, the analysis also predicts increased formation of trichloroacetyl chloride with hydrogen elimination and back reaction to the original reactants.
\end{abstract}

\section{Introduction}

Past and present manufacturing and disposal practices have resulted in the release of tetrachloroethylene into the atmosphere at significant rates. The amount of this highly volatile compound emitted in the U.S. alone was estimated to be $\sim 1 \times 10^{5}$ metric tons annually by Gilbert et al. ${ }^{1}$ Knowledge of reactions facilitating the breakdown of this compound is necessary to both predict the natural decomposition that is occurring in the atmosphere and determine appropriate disposal practices.

The dominant atmospheric loss reaction is expected to be the reaction with $\mathrm{OH}$ radicals since chloroethenes do not absorb radiation at wavelengths of $>300 \mathrm{~nm}$, nor do they react significantly with $\mathrm{O}_{3}$ or $\mathrm{NO}_{3}$ in the gas phase. ${ }^{2-4}$ Rate constants including the tropospheric temperature range $(220-300 \mathrm{~K})$ have been reported previously, and the work reported here validates those rate expressions. ${ }^{5-8}$

High-temperature incineration is considered to be the best available technology for the safe disposal of these toxic compounds. The fastest process contributing to the destruction of unsaturated halogenated hydrocarbons is the reaction with $\mathrm{OH}$ radicals. ${ }^{9,10}$ Given the importance of the high-temperature reaction of the $\mathrm{OH}$ radical with chloroethenes both in natural and planned decomposition, knowledge of the reaction rate

* Corresponding author. Phone: (937) 229-3604. Fax: (937) 229-2503. E-mail: Taylorp@udri.udayton.edu. constants and reaction mechanisms over an extended temperature range is essential to predict the true nature of the breakdown products.

Previous studies have predicted rates for $\mathrm{C}_{2} \mathrm{Cl}_{4}$ up to $433 \mathrm{~K} .^{7,8}$ We present high-precision rate coefficients for the reaction of $\mathrm{OH}$ with $\mathrm{C}_{2} \mathrm{Cl}_{4}\left(k_{1}\right)$ over an extended temperature range of 298$720 \mathrm{~K}$,

$$
\mathrm{C}_{2} \mathrm{Cl}_{4}+\cdot \mathrm{OH} \rightarrow \text { products }
$$

Two- and three-parameter Arrhenius coefficients were determined empirically for $\mathrm{C}_{2} \mathrm{Cl}_{4}$, whereas the predicted mechanisms were conceptualized using $\mathrm{ab}$ initio calculations to define the activated complexes and transient states, and thus predict the most likely path and products. Quantum Rice-RamspergerKassel (QRRK) analysis was used to predict the temperature and pressure dependence of the individual paths and the overall reaction dependence. ${ }^{11}$

\section{Experimental Approach and Data Reduction}

The experimental procedures were similar to those used in previous studies of the reaction of $\mathrm{OH}$ radicals with halogenated hydrocarbons ${ }^{12-14}$ (see Figures 1 and 2). In the present study, a XeF excimer laser (Lamba Physik Compex model 102) was used to produce $\mathrm{OH}$ radicals by $351 \mathrm{~nm}$ photodissociation of nitrous acid (HONO) to form nitric oxide and the hydroxyl 


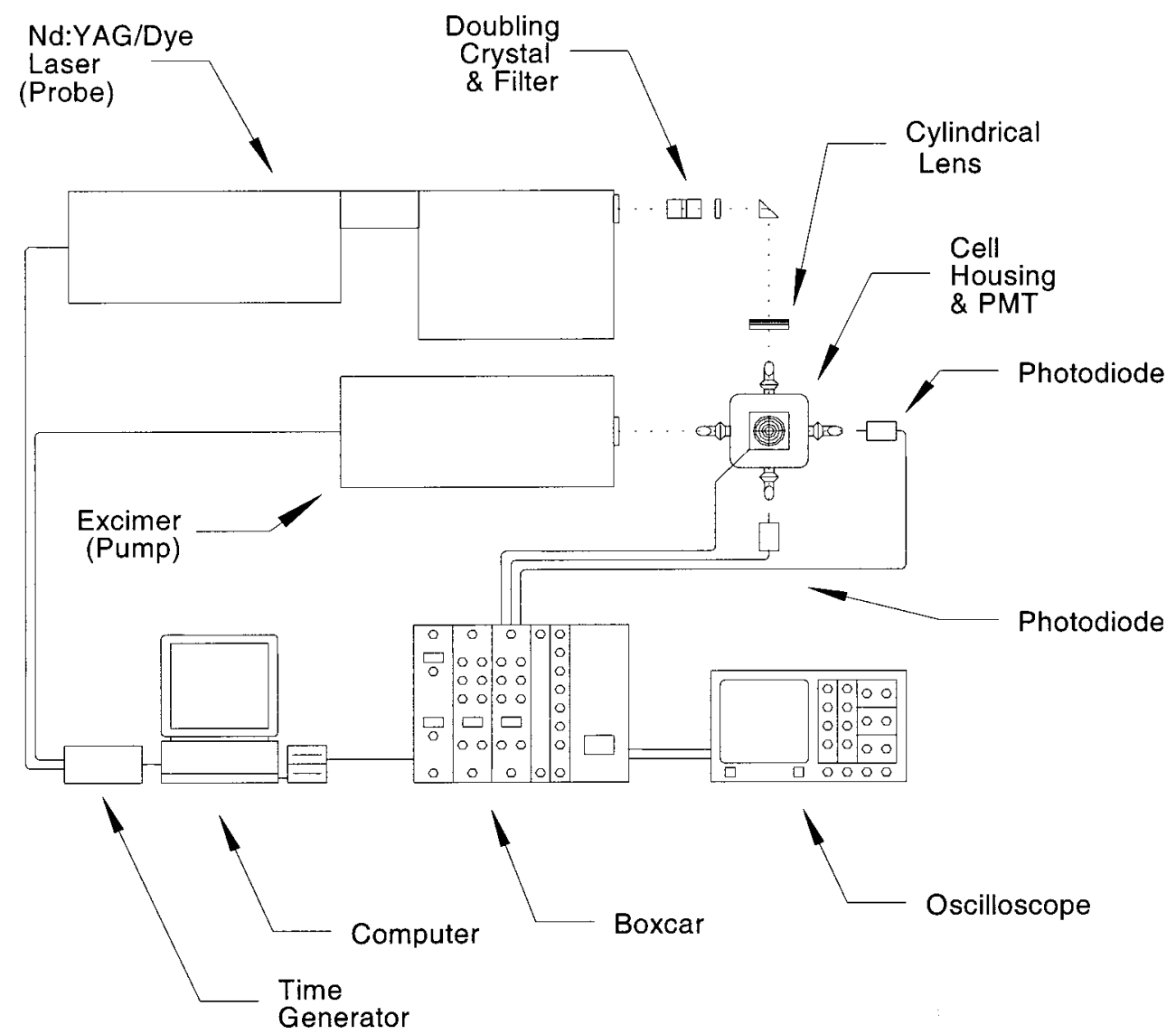

Figure 1. Schematic drawing of the LP/LIF system.

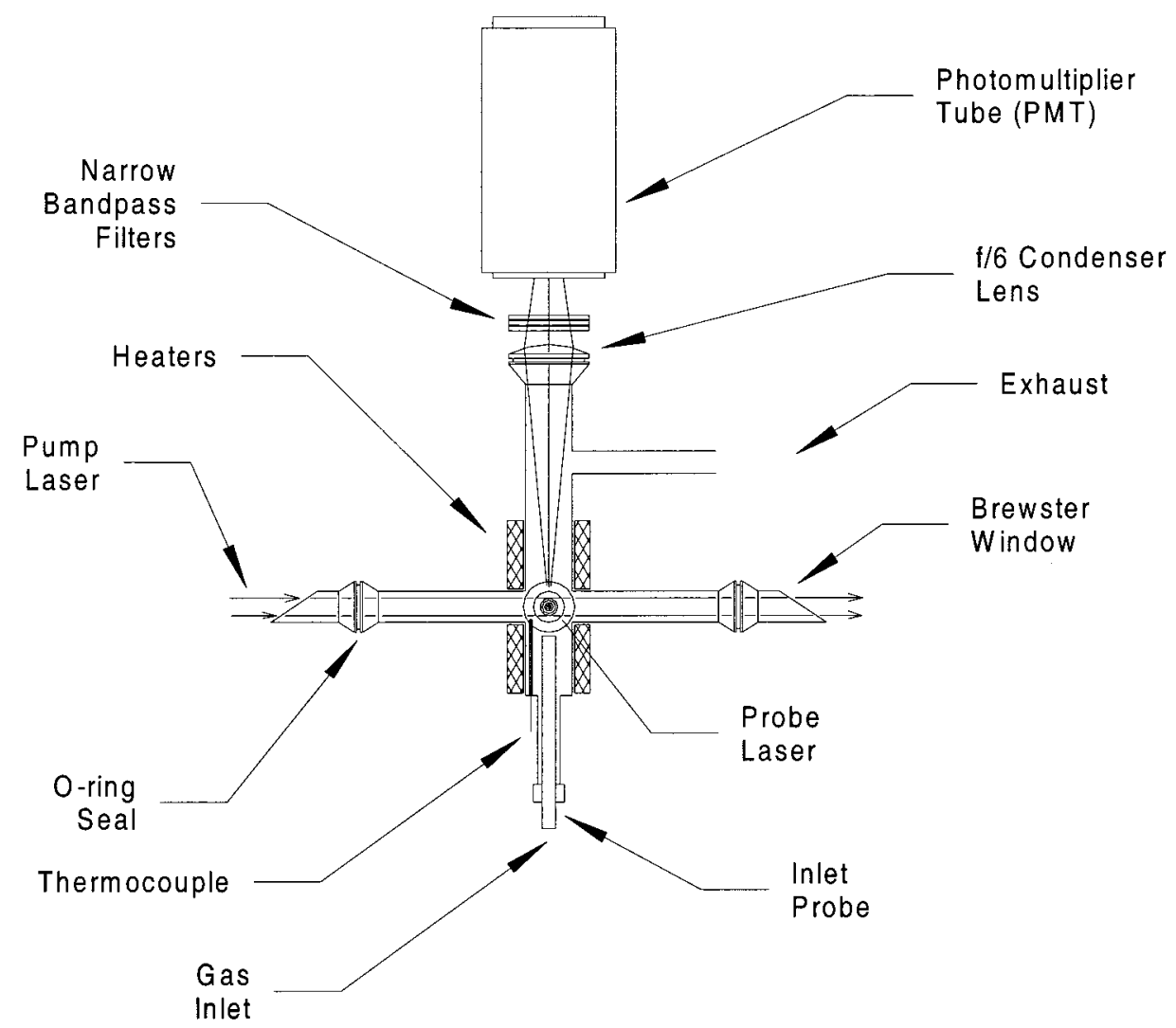

Figure 2. Two-dimensional schematic drawing of the optical reactor. The optical path of the Nd:YAG pumped dye laser is perpendicular to the plane of the figure and intersects the excimer laser beam in the center of the reactor.

radical. A competing dissociation channel, production of $\mathrm{NO}_{2}$ and $\mathrm{H}$ atoms has been observed to be negligible under similar experimental conditions. ${ }^{15}$ Initial $[\mathrm{OH}]_{0}$ ranged from $\sim 3 \times 10^{10}$ to $9.0 \times 10^{10}$ molecules $\mathrm{cm}^{-3}$, and was determined based on 


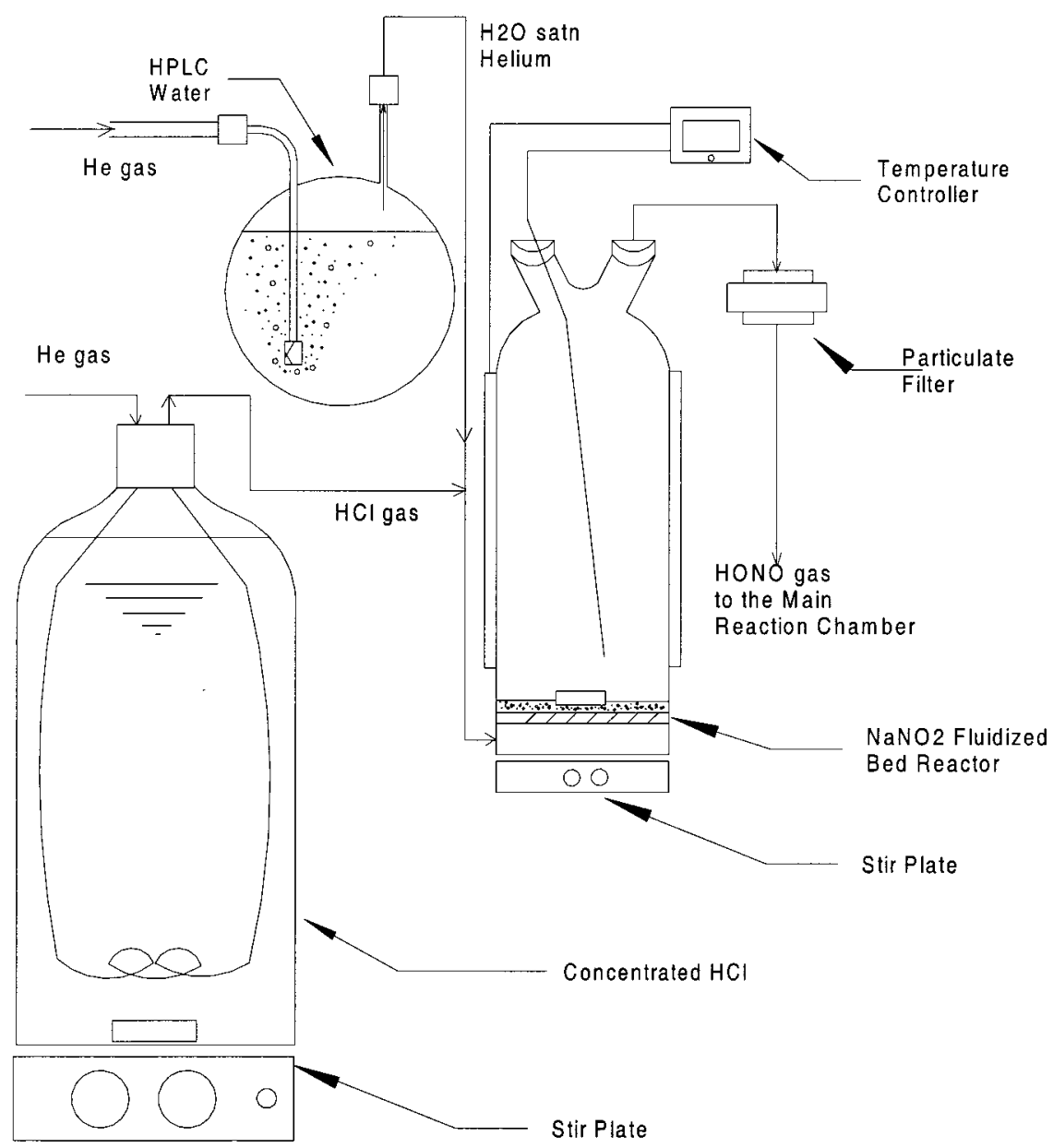

Figure 3. Schematic drawing of the HONO generation system.

the measured excimer fluence, the published value of the absorption cross section for HONO, $21.2 \times 10^{-20} \mathrm{~cm}^{2} /$ molecule at $351 \mathrm{~nm},{ }^{16}$ a quantum yield of $1.0,{ }^{17}$ and measurements of $\left[\mathrm{NO}_{2}{ }^{-}\right]$(taken to represent [HONO]) determined using ion chromatography. The laser fluence was typically on the order of $8.5 \mathrm{~mJ} \mathrm{~cm}^{-2}$ with a beam input filling the reaction chamber along the photolysis beam axis. [HONO] varied between 1 and $3 \times 10^{13}$ molecules $\mathrm{cm}^{-3}$ with an overall HONO generation rate averaging 97.6 nmole $\mathrm{min}^{-1}$.

The probe beam system was responsible for creating the fluorescence of the $\mathrm{OH}$ radical and permitting subsequent monitoring of its relative concentration as a function of time. A Quanta Ray model DCR-1/PDL-1 pulsed Nd:YAG pumped dye laser was used as the probe beam source which, after shifting and doubling, produced a beam of wavelength $282.15 \mathrm{~nm}$. A laser fluence of $\sim 500 \mu \mathrm{J} /$ pulse was measured as it entered the optical reactor. $\mathrm{OH}$ emission was collected at $308 \mathrm{~nm}$ with a PMT/band-pass filter combination and fed to a Stanford Research Systems gated integrator and boxcar averager.

The method used to generate the precursor for the hydroxyl radical varied from previous experimentation. Initial testing of $\mathrm{C}_{2} \mathrm{Cl}_{4}$ was performed using $193 \mathrm{~nm}$ photolysis of $\mathrm{N}_{2} \mathrm{O} / \mathrm{H}_{2} \mathrm{O}$ mixtures as the $\mathrm{OH}$ source, as had been done previously. ${ }^{12-14}$ The resulting room-temperature rate measurements exceeded previously reported values by a factor of $10.5^{5-8}$ Because of the large absorption cross section of $\mathrm{C}_{2} \mathrm{Cl}_{4}\left(\sim 8 \times 10^{-18} \mathrm{~cm}^{2}\right.$ molecule $\left.{ }^{-1}\right),{ }^{18}$ additional measurements were conducted at low excimer laser fluences $\left(<1 \mathrm{~mJ} \mathrm{~cm}^{-2}\right)$, with no observed reduction in rate coefficients. These results made operation at $193 \mathrm{~nm}$ unacceptable and necessitated the use of a different
$\mathrm{OH}$ generation method when evaluating $\mathrm{C}_{2} \mathrm{Cl}_{4}$ and the hydrogensubstituted family of chloroethenes.

Gaseous HONO was produced by the reaction of gaseous $\mathrm{HCl}$ with solid $\mathrm{NaNO}_{2}$ in a continuously stirred tank reactor (Figure 3), as suggested by the recent work of Febo et al. ${ }^{19}$ Consistent with this work, it was found that a temperature of $50{ }^{\circ} \mathrm{C}$ produced maximum yield. Adjustments were made as needed to keep the reactor in the range of $50 \pm 0.5{ }^{\circ} \mathrm{C}$. A Millipore Teflon filter was installed in the exit line to trap any carryover of the solid. It was necessary to change this filter approximately every 3 weeks. Replacement of the $\mathrm{NaNO}_{2}$ after approximately $25 \mathrm{~h}$ of operation facilitated consistent $\mathrm{HONO}$ production. Continuous, vigorous stirring of the $\mathrm{NaNO}_{2}$ improved the overall conversion rate and extended the life of the reactor significantly by minimizing the amount of absorbed HONO. To avoid the introduction of another reactant into the $\mathrm{C}_{2} \mathrm{Cl}_{4} / \mathrm{OH}$ reaction zone, it was important to keep the concentration of $\mathrm{HCl}$ in the exit stream of the $\mathrm{HONO}$ reactor to a minimum. Optimized operating design and conditions kept $[\mathrm{HCl}]$ below measurable levels $(<0.05 \mathrm{ppm})$ yet allowed three full days of operation before replacement of the sodium nitrite.

Once produced, the HONO gas exited the HONO reactor through the Teflon filter before joining the carrier gas makeup line (helium). This line was used to adjust the overall volumetric flow rate through the main reactor cell from a minimum of approximately 210 up to a maximum of $1200 \mathrm{~cm}^{3} \mathrm{~min}^{-1}$. Tetrachloroethylene was injected into this line prior to entering the main reactor. The temperature of the reaction volume was maintained with a thermoelectric heater that surrounded the reactor. This heater was fitted with a feedback, time-proportion- 
ing temperature controller. Temperature was measured with a chrome/alumel thermocouple positioned $\sim 2 \mathrm{~mm}$ from the probe intersection volume. Measurements using a second thermocouple capable of being positioned at varying radial locations within the reactor indicated a variation of $\leq 3.1 \mathrm{~K}$ across the detection volume.

The reaction of the hydroxyl radical with $\mathrm{C}_{2} \mathrm{Cl}_{4}$ occurred within the probe intersection volume where the pump and probe laser beams crossed. The reaction occurred under slow flow conditions, with the total flow of the gas controlled through the sum of $\mathrm{He}$ lines feeding the $\mathrm{HCl}$ stream, the water impinger, and the carrier stream. A separate source fed the $\mathrm{HCl}$ diffusion line to avoid contaminating the HPLC water located in the impinger. The flows of these three lines were each controlled by differential mass flow controllers, with the total flow out of the reactor measured both before and after the series of runs with a soap film flow meter. The combined gas stream, including the $\mathrm{He} / \mathrm{HONO} / \mathrm{C}_{2} \mathrm{Cl}_{4} / \mathrm{HCl}$ (trace)/residual $\mathrm{H}_{2} \mathrm{O}$, entered the reactor through an injection tube with the outlet positioned just below the reaction volume. The injector tube was used to reduce the amount of entry gas heating. This was most important at temperatures exceeding $720 \mathrm{~K}$ where the HONO experienced some thermal degradation.

After being cleaned, dried, and filled with helium at atmospheric pressure, $1 \mathrm{~L}$ gas bulbs were used to prepare the stock organic gas samples. Initial partial pressures of $\mathrm{C}_{2} \mathrm{Cl}_{4}$ ranged from 9.2 to 18.3 Torr. These partial pressures, based on measured flow rates before and after each experiment, correspond to a range of $5.0 \times 10^{13}$ to $1.0 \times 10^{15}$ molecules $\mathrm{cm}^{-3}$.

All experiments were conducted at a total pressure of $740 \pm$ 10 Torr. Samples of $\mathrm{C}_{2} \mathrm{Cl}_{4}$ were obtained from Aldrich with 99.9\% purity. Gas chromatography-mass spectrometry (GC/ MS) analyses indicated that this purity was met or exceeded. The absorption cross section for $\mathrm{C}_{2} \mathrm{Cl}_{4}$ decreases below $10^{-20}$ $\mathrm{cm}^{2}$ molecule $\mathrm{e}^{-1}$ as the wavelength increases from 230 to 310 $\mathrm{nm},{ }^{20}$ indicating that laser photolysis of the reactants was insignificant. The $\mathrm{C}_{2} \mathrm{Cl}_{4}$ and helium sample was introduced into the entering gas stream via a calibrated syringe pump (Sage Instruments, 341B) with flow rates varying between 0.10 and $2.61 \mathrm{~mL} \mathrm{~min} \mathrm{~m}^{-1}$ and a mixing time in the range of 0.13 to 0.90 $\mathrm{s}$ before entering the detection volume. Some difficulty was experienced with the sample in terms of conditioning the injector tube surface. This problem was dealt with by running a full 10 $\mathrm{mL}$ syringe of $\mathrm{C}_{2} \mathrm{Cl}_{4}$ through the injector before starting to collect data, and beginning at the highest syringe pump setting and working down to lower settings.

The rate of disappearance of the $\mathrm{OH}$ may be presented as

$$
-\mathrm{d}[\mathrm{OH}] / \mathrm{d} t=k_{1}\left[\mathrm{C}_{2} \mathrm{Cl}_{4}\right][\mathrm{OH}]+k_{\mathrm{d}}[\mathrm{OH}]
$$

where $k_{1}$ is the bimolecular rate constant and $k_{\mathrm{d}}$ is the firstorder rate for the reaction of $\mathrm{OH}$ with impurities and diffusion out of the reaction volume. This relationship holds in the absence of any secondary reactions that may form or deplete $\mathrm{OH}$. Solution of this equation yields $[\mathrm{OH}]=[\mathrm{OH}]_{0} \exp \left(-k^{\prime} t\right)$, where $k^{\prime}=k_{1}\left[\mathrm{C}_{2} \mathrm{Cl}_{4}\right]+k_{\mathrm{d}}$. For all experiments, reactive and diffusive $\mathrm{OH}$ radical decay profiles exhibited exponential behavior and were fitted by the following nonlinear expression:

$$
[\mathrm{OH}]=[\mathrm{OH}]_{0} \exp \left(-k^{\prime} t\right)+\gamma
$$

where $\gamma$ is the constant background signal level and $t$ is the time delay between the two lasers. Because the $\mathrm{C}_{2} \mathrm{Cl}_{4}$ concentration was much greater than that of $\mathrm{OH}(\sim 100$ to 1000 times in excess), pseudo-first-order exponential $\mathrm{OH}$ decays were

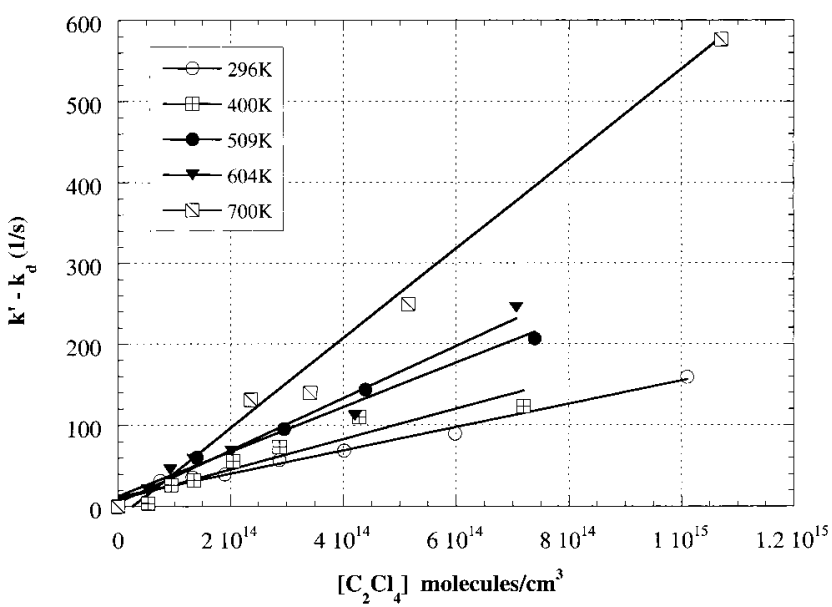

Figure 4. Pseudo-first-order rate constant, $k^{\prime}-k_{\mathrm{d}}$, as a function of $\left[\mathrm{C}_{2} \mathrm{Cl}_{4}\right]$ at various temperatures.

TABLE 1: Absolute Rate Coefficients for $k_{1}{ }^{a}$

\begin{tabular}{cccc}
\hline $\begin{array}{c}\text { temperature } \\
(\mathrm{K})\end{array}$ & $\left.\begin{array}{c}10^{13} k_{2}\left(\mathrm{~cm}^{3}\right. \\
\text { molecule }\end{array} \mathrm{s}^{-1}\right)$ & $\begin{array}{c}\text { temperature } \\
(\mathrm{K})\end{array}$ & $\begin{array}{c}10^{13} k_{2}\left(\mathrm{~cm}^{3}\right. \\
\left.\text { molecule }^{-1} \mathrm{~s}^{-1}\right)\end{array}$ \\
\hline 296.5 & $1.45 \pm 0.16$ & 555 & $3.49 \pm 0.40$ \\
327 & $1.63 \pm 0.42$ & 604 & $3.52 \pm 0.62$ \\
354 & $1.88 \pm 0.64$ & 646 & $3.57 \pm 0.26$ \\
400 & $2.25 \pm 0.50$ & 658 & $6.20 \pm 0.92$ \\
442 & $2.48 \pm 0.46$ & 700 & $5.43 \pm 0.68$ \\
509 & $3.75 \pm 0.64$ & 714 & $6.71 \pm 1.50$
\end{tabular}

${ }^{a}$ Errors represent $\pm 2 \sigma$ and do not include the 5-10\% uncertainty estimated for possible systematic errors.

observed and the individual temperature-dependent rate constants, $k_{1}$, were determined as the slopes of the least-squares fits of $k^{\prime}$ versus $\left[\mathrm{C}_{2} \mathrm{Cl}_{4}\right]$. $\mathrm{OH}$ decays were measured over two to three decay lifetimes over a time interval of 0.2 to $30.0 \mathrm{~ms}$. Values of $k_{\mathrm{d}}$ were measured before and after a rate determination and were observed to be constant within experimental uncertainties $( \pm 10 \%)$, indicating that the HONO source was stable over the course of an experiment. Typical values of $k_{\mathrm{d}}$ decreased from $\sim 200 \mathrm{~s}^{-1}$ at low temperatures to $\sim 100 \mathrm{~s}^{-1}$ at elevated temperatures. Refer to Figure 4 for a plot of $k^{\prime}-k_{\mathrm{d}}$ vs $\left[\mathrm{C}_{2} \mathrm{Cl}_{4}\right]$ for several temperatures tested.

\section{Experimental Results}

Absolute rate coefficients for $k_{1}$ are presented in Table 1. Random error limits $( \pm 2 \sigma)$ were below $20 \%$ at most temperatures. Rates were measured for a wide range of initial concentrations and included an order of magnitude concentration difference for each series of runs. Initial $\mathrm{C}_{2} \mathrm{Cl}_{4}$ concentrations were based on real gas adjustments to the ideal gas law. This partial pressure was checked with a capacitance manometer (MKS Baratron Type 622 and MKS Type PDR-D-122A) for each reactant over the full range of partial pressures; all readings were within the error of the transducer ( \pm 1.9 Torr).

When reporting an absolute rate constant by measuring the concentration of a single reactant, it is important to be aware of pathways available for this reactant with the various species present in the reaction zone. When identifying possible side reactions, two reactions of concern are hydroxyl and/or a $\mathrm{C}_{2} \mathrm{Cl}_{4}$ combination with $\mathrm{HONO}$ and $\mathrm{H}_{2} \mathrm{O}$. Water vapor was present in the system as carryover from the HONO reactor. These and other possible side reactions were simulated numerically using reaction rate constants published in the NIST Chemical Kinetics Database. ${ }^{21}$ The results of this analysis indicated that side reactions would not impact significantly on the reaction under 


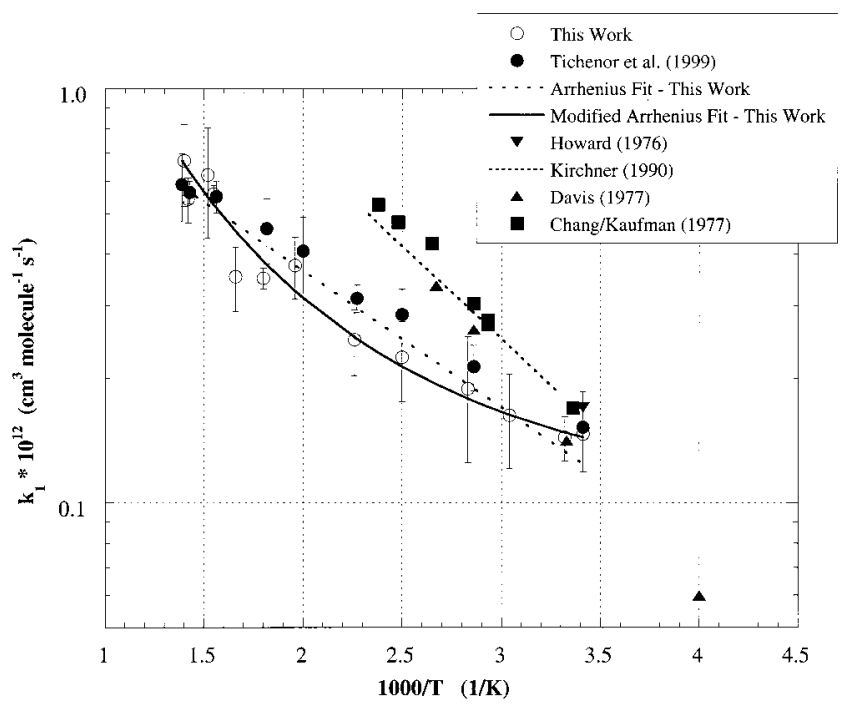

Figure 5. Arrhenius plot of kinetic data for $k_{1}$. Also shown are the results of previous studies, a best-fit Arrhenius expression, and a best fit modified-Arrhenius expression. ( $P=740 \pm 10$ Torr $)$.

observation with the input concentrations and experimental conditions used. In the absence of reactant impurities, sources of systematic error were then limited to thermally induced secondary reactions. The possibility of thermally generated side products was investigated by varying the total gas flow rate. The rate constant, $k_{1}$, was found to be independent of the residence time in the mid- to high-temperature regions, implying a lack of thermal reaction of the substrates in this zone. Above $720 \mathrm{~K}$, we did experience an excess of $\mathrm{OH}$ radical generation at reduced flow rates. This was evidenced by a substantial $\mathrm{OH}$ signal without excimer laser input, and a subsequent dramatic drop in the signal with the introduction of organic (once again without photolytic production of $\mathrm{OH}$ ). Subsequent work has indicated that a higher overall flow rate may reduce the significance of thermally generated $\mathrm{OH} .{ }^{22}$

All known experimental measurements for $k_{1}$ are summarized in Figure 5. The present work extends experimental measurement beyond the earlier reported limit of $\sim 430 \mathrm{~K}$. A variety of techniques were used in collecting these data. Examination of Figure 5 shows close agreement, at room temperature, between our work and previous studies. ${ }^{5-8}$ (Data collected using the relative rate method has not been included in our comparison.) An Arrhenius fit yielded the expression $k_{1}(T)=(1.68 \pm 0.25)$ $\times 10^{-12} \exp (-764.2 \pm 79.1 / T)$, and a three-parameter Arrhenius fit yielded $k_{1}(T)=(1.93 \pm 0.20) \times 10^{-22}(T)^{3.2} \exp (660.8 \pm$ $54.6 / T$ ), where $k_{1}$ is in units of $\mathrm{cm}^{3}$ molecule ${ }^{-1} \mathrm{~s}^{-1}$. The threeparameter fit is a slightly better statistical fit to the data. As the temperature increases, the difference between our values and those from the other studies increases. Previous studies have indicated that this reaction is not pressure dependent; ${ }^{8}$ therefore, the fact that the other studies were performed at low pressures ( $\sim 2$ Torr) should not have a bearing on our comparison. A physical explanation for the difference may be related to the surface absorptive behavior of $\mathrm{C}_{2} \mathrm{Cl}_{4}$. Measurements at or near room temperature required extensive passivation of the injector prior to collecting reliable data. This was accomplished by injecting full syringes of the organic sample into the reactant stream and collecting data for the higher $\left[\mathrm{C}_{2} \mathrm{Cl}_{4}\right]$ runs first, then moving to the lower settings. If this experimental practice was not followed, meaningful correlations between $k^{\prime}$ and the $\mathrm{C}_{2} \mathrm{Cl}_{4}$ concentration were not observed. This same affinity for the injector tube walls was not observed at the higher temperatures when collecting the data. When comparing our method with that of the discharge flow technique, their measurements were made in a precoated reactor that supposedly minimized surface retention of the reactants. ${ }^{7,8}$ However, in the event that $\mathrm{C}_{2} \mathrm{Cl}_{4}$ absorption was not minimized in the discharge flow experiments, erroneously high rate measurements may have occurred. This explanation cannot be applied to the flash photolysis results of Davis et al.; ${ }^{6}$ in this case the reason for the discrepancy in the temperature dependence of the rate measurements is unclear. Our data are consistent over all temperatures and yielded, with small scatter, modified Arrhenius behavior. Surface absorption effects were minimized, if not eliminated, in our experimental technique, giving rise to a more accurate rate expression for this reaction.

\section{Theoretical Modeling}

In addition to direct measurement of the rate expression for the reaction of $\mathrm{C}_{2} \mathrm{Cl}_{4}$ with $\mathrm{OH}$, the reaction pathways and kinetics were analyzed using theoretical thermodynamic properties. These properties, $\Delta_{\mathrm{f}} H^{\circ}{ }_{298}, S^{\circ}{ }_{298}$, and $C_{\mathrm{p}}(T)$ over $300 \mathrm{~K} \leq$ $T \leq 2000 \mathrm{~K}$, were calculated based on optimized geometries, frequencies, and total energies derived by several ab initio methods, using the Gaussian94 computer code. ${ }^{23}$ Calculations were mainly performed by a SGI Origin 2000 high-performance computer residing at the Ohio Supercomputer Center. Thermodynamic properties and kinetic parameters were determined for reactants, intermediate radicals, transition states (TSs), and products.

The potential energy diagram for these intermediate states and subsequent products is shown in Figure 6 . The geometries of the $\mathrm{C}_{2} \mathrm{Cl}_{4}+\mathrm{OH}$ stabilized adduct and the transition state, $\mathrm{CCl}_{2} \cdots \mathrm{Cl} \cdots \mathrm{CClOH}$ (where chlorine is transferred to the carbon radical site by forming a cyclical structure between the $\mathrm{Cl}$ and $\mathrm{C}^{\bullet}$ ), are shown in Figure 7.

The potential energy diagram was evaluated using G3(MP2) ${ }^{24}$ theory for all structures with the exception of $\mathrm{CCl}_{2} \cdots \mathrm{Cl} \cdots$ $\mathrm{CClOH}$ (TS1), $\mathrm{CCl}_{3} \mathrm{CClO} \cdots \mathrm{H}$ (TS2), and the intermediate isomer $\mathrm{CCl}_{2} \mathrm{HCCl}_{2} \mathrm{O}^{\circ}$, because of convergence failures for these three species at the higher level of theory. The activation energy of the entrance channel (TS0) was estimated using the higher level calculation, $\mathrm{G} 3,{ }^{25}$ since this channel determines the $\mathrm{OH}$ decay rate and is the most critical of the reaction mechanisms. The energies of TS2 and $\mathrm{CCl}_{2} \mathrm{HCCl}_{2} \mathrm{O}^{\bullet}$ were estimated using the MP2(full)/6-31G(d) level of theory, and the activation energy for TS1 was evaluated at the B3LYP/6-31G(d) level of theory. All of the energy calculations, except for these three, were estimated using the reactants as the basis for the relative energy difference. The TS2 energy was evaluated using the products as a reference for the energy difference and applying MP2(full)/6-31G(d) level of theory, while the TS1 energy level was evaluated using the energy difference between the isomer, $\mathrm{CCl}_{3} \mathrm{C}^{\bullet} \mathrm{ClOH}$, and TS1 and applying B3LYP/6-31G(d) theory. The isomer $\mathrm{CCl}_{2} \mathrm{HCCl}_{2} \mathrm{O}$ ' was evaluated using the energy difference from $\mathrm{C}^{\bullet} \mathrm{Cl}_{2} \mathrm{CCl}_{2} \mathrm{OH}$ with MP2(full)/6-31G(d) theory.

The entropy $S^{\circ} 298$ and heat capacities $C_{\mathrm{p}}(T)$ were calculated based on HF/6-31G(d) optimized geometries and frequencies using statistical mechanics except TS1. Those for TS1 were calculated based on B3LYP/6-31G(d) optimized geometry and frequencies. The G3 method incorporated the HF/6-31G(d) level of frequencies and MP2(full)/6-31G(d) optimized geometries followed by single-point calculations of MP4/6-31G(d), QCISD(T)/6-31G(d), and MP2(fc)/G3large energies. The G3(MP2) method relied on the same frequency and geometry optimization methods as G3, followed by single-point calculations of QCISD(T)/6-31G(d) and MP2(fc)/G3MP2large energies. Both a zero- 


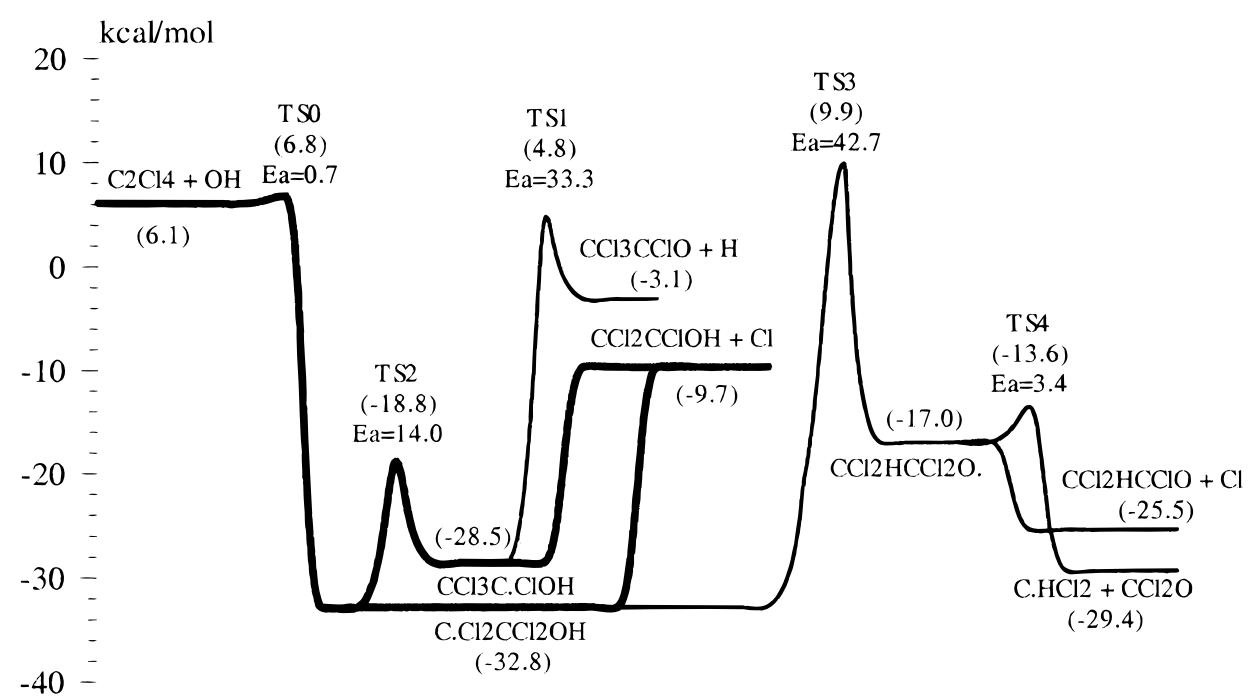

Figure 6. Potential energy diagram for the $\mathrm{OH}$ addition to $\mathrm{C}_{2} \mathrm{Cl}_{4}$. Energies are $\Delta H_{\mathrm{f}}{ }^{\circ} 298$ in $\mathrm{kcal} / \mathrm{mol}$. Adduct stabilization, isomerization, and $\mathrm{H}$ and $\mathrm{Cl}$ atom elimination channels are shown. Energy was evaluated using G3(MP2) theory except for TS1 (MP2(full)/6-31G(d)), TS2 (B3LYP/6-31G(d)), and the intermediate isomer $\mathrm{CCl}_{2} \mathrm{HCCl}_{2} \mathrm{O}^{\bullet}(\mathrm{MP} 2(\mathrm{full}) / 6-31 \mathrm{G}(\mathrm{d})$ ).

(a)

a)

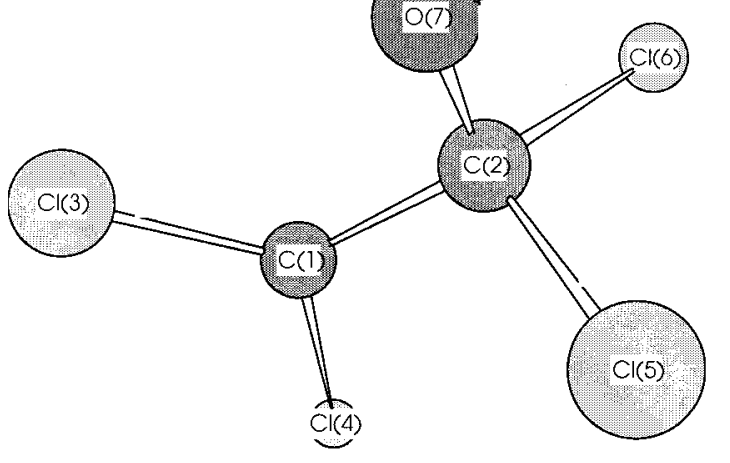

\begin{tabular}{cccc}
\hline Bond Length & $\AA$ & Bond Angle & Degree \\
\hline $\mathrm{C} 1-\mathrm{C} 2$ & 1.499 & $\angle \mathrm{C} 1 \mathrm{C} 2 \mathrm{Cl} 3$ & 117.4 \\
$\mathrm{C} 1-\mathrm{Cl} 3$ & 1.698 & $\angle \mathrm{C} 1 \mathrm{C} 2 \mathrm{Cl} 4$ & 118.8 \\
$\mathrm{C} 1-\mathrm{Cl} 4$ & 1.698 & $\angle \mathrm{C} 1 \mathrm{C} 2 \mathrm{Cl} 5$ & 110.3 \\
$\mathrm{C} 2-\mathrm{Cl} 5$ & 1.815 & $\angle \mathrm{C} 1 \mathrm{C} 2 \mathrm{Cl6}$ & 109.9 \\
$\mathrm{C} 2-\mathrm{Cl} 6$ & 1.792 & $\angle \mathrm{C} 1 \mathrm{C} 2 \mathrm{O} 7$ & 107.7 \\
$\mathrm{C} 2-\mathrm{O} 7$ & 1.368 & $\angle \mathrm{C} 2 \mathrm{O} 7 \mathrm{H} 8$ & 108.3 \\
$\mathrm{O} 7-\mathrm{H} 8$ & 0.977 & & \\
$\mathrm{C} 1-\mathrm{Cl6}$ & 2.699 & & \\
\hline
\end{tabular}

(b)

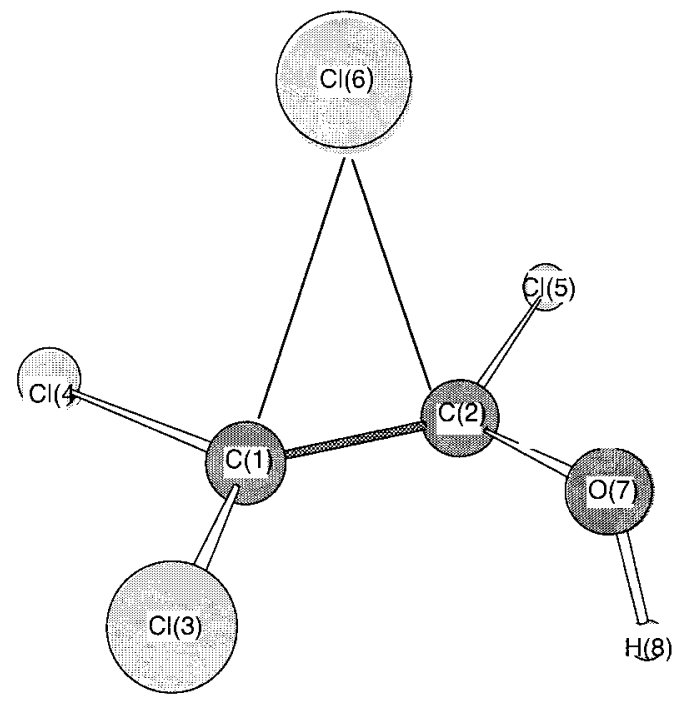

Figure 7. Calculated geometries for the $\mathrm{C}_{2} \mathrm{Cl}_{4}+\mathrm{OH}$ stabilized adduct, MP2(full)/6-31G(d) level of theory (a) and the Cl shift transition state, B3LYP/6-31G(d) level of theory (b).

point vibrational energy scaling factor $(x=0.8929)$ and a thermal correction to $298 \mathrm{~K}$ for the enthalpies of formation were incorporated.

The high-pressure limit $A$ factors of unimolecular reactions were calculated using conventional transition state theory (TST). ${ }^{26}$ Loss (or gain) of internal rotors and change of symmetry numbers were incorporated into the calculation of
$S^{\circ}{ }_{298}$ for each TS. $S^{\circ}{ }_{298}$ of reactants and transition states were then used to determine the pre-exponential factor, $A$.

The modified Arrhenius expression for initial formation of the $\mathrm{OH}+\mathrm{C}_{2} \mathrm{Cl}_{4}$ adduct was determined from ab initio $\mathrm{HF} /$ 6-31G(d) geometries and frequencies for the activated complex and reactants, together with the G3 energy barrier. This barrier was subsequently decreased by $0.6 \mathrm{kcal} / \mathrm{mol}$, well within the 
TABLE 2: Input QRRK Parameters

\begin{tabular}{|c|c|c|c|c|}
\hline & reaction & $\begin{array}{l}B\left(\mathrm{~s}^{-1} \text { or } \mathrm{cm}^{3} /\right. \\
(\text { molecules } \mathrm{s}))\end{array}$ & $n$ & $\begin{array}{c}C \\
(\mathrm{kcal} / \mathrm{mol})\end{array}$ \\
\hline 1 & $\mathrm{C}_{2} \mathrm{Cl}_{4}+\mathrm{OH} \Rightarrow \mathrm{C}^{\bullet} \mathrm{Cl}_{2} \mathrm{CCl}_{2} \mathrm{OH}$ & $9.90 \mathrm{E}-21$ & 2.69 & -1.4 \\
\hline-1 & $\mathrm{C}^{\circ} \mathrm{Cl}_{2} \mathrm{CCl}_{2} \mathrm{OH} \Longrightarrow \mathrm{C}_{2} \mathrm{Cl}_{4}+\mathrm{OH}$ & $2.47 \mathrm{E}-13$ & 0.88 & 39.5 \\
\hline 2 & $\mathrm{C}^{\cdot} \mathrm{Cl}_{2} \mathrm{CCl}_{2} \mathrm{OH} \Rightarrow \mathrm{CCl}_{3} \mathrm{C}^{\cdot} \mathrm{ClOH}$ & $1.81 \mathrm{E}-12$ & 0.26 & 14.4 \\
\hline-2 & $\mathrm{CCl}_{3} \mathrm{C}^{\bullet} \mathrm{ClOH} \Rightarrow \mathrm{C}^{\bullet} \mathrm{Cl}_{2} \mathrm{CCl}_{2} \mathrm{OH}$ & $9.53 \mathrm{E}-14$ & 0.71 & 9.8 \\
\hline 3 & $\mathrm{CCl}_{3} \mathrm{C}^{\bullet} \mathrm{ClOH} \Longrightarrow \mathrm{CCl}_{3} \mathrm{CClO}+\mathrm{H}$ & $9.55 \mathrm{E}-15$ & 1.58 & 33.0 \\
\hline 4 & $\mathrm{CCl}_{3} \mathrm{C}^{\bullet} \mathrm{ClOH} \Rightarrow \mathrm{CCl}_{2} \mathrm{CClOH}+\mathrm{Cl}$ & $2.81 \mathrm{E}-11$ & 0.00 & 18.8 \\
\hline 5 & $\mathrm{C}^{\circ} \mathrm{Cl}_{2} \mathrm{CCl}_{2} \mathrm{OH} \Rightarrow \mathrm{CCl}_{2} \mathrm{HCClO}+\mathrm{Cl}$ & $2.81 \mathrm{E}-11$ & 0.00 & 23.5 \\
\hline 6 & $\mathrm{C}^{\bullet} \mathrm{Cl}_{2} \mathrm{CCl}_{2} \mathrm{OH} \Rightarrow \mathrm{CCl}_{2} \mathrm{CClOH}+\mathrm{Cl}$ & $2.91 \mathrm{E}-15$ & 0.89 & 42.7 \\
\hline
\end{tabular}

grouped geometric mean frequencies of the adduct with effective degeneracies:

$337.2 \mathrm{~cm}^{-1}$ (8.580), $401.1 \mathrm{~cm}^{-1}$ (3.871), $1285.2 \mathrm{~cm}^{-1}$ (4.550)

Lennard-Jones parameters:

$\mathrm{C}_{2} \mathrm{Cl}_{4} \mathrm{OH}$ adduct, $\sigma=6.056 \AA, \epsilon / k=564.3 \mathrm{~K}$

He bath gas, $\sigma=2.576 \AA$, $\epsilon / k=470.0 \mathrm{~K}$

reliability of such ab initio calculations, to result in an expression that more closely matched the experimental results, $k_{\mathrm{TST}}=9.90$ $\times 10^{-21} T^{2.69} \exp (+689 / T) \mathrm{cm}^{3}$ molecule ${ }^{-1} \mathrm{~s}^{-1}$. This expression gives $k$ values to within $10 \%$ of those from the three parameter fit to the experimental results (5\% rms deviation).

In the bimolecular transition state theory calculations, all the vibrational modes were treated as harmonic oscillators, except for two. The lowest mode at $58 \mathrm{~cm}^{-1}$ corresponds to torsion about the $\mathrm{C}-\mathrm{C}$ bond in the transition state, and using the relationship of Benson, ${ }^{26}$ we derived a barrier to internal rotation with a 2-fold degeneracy of $12.8 \mathrm{kcal} / \mathrm{mol}$. The barrier height was confirmed by reoptimizing the TS to a second-order saddle point, where the two $\mathrm{CCl}_{2}$ moieties are close to perpendicular. At the HF/6-31G(d) level, the zero-point energy corrected geometry was $12.4 \mathrm{kcal} / \mathrm{mol}$ above the TS geometry. This value for the barrier to hindered internal rotation was employed with the tables of Lewis et al. ${ }^{27}$ to derive the partition functions and entropy for this internal mode of the TS. Similarly, the hindered torsion of the hydroxyl group around the forming $\mathrm{C}-\mathrm{O}$ bond, with a frequency of $204 \mathrm{~cm}^{-1}$, has a corresponding ${ }^{26}$ barrier of $6.0 \mathrm{kcal} / \mathrm{mol}$ and was also taken into account when determining the overall molecular partition function. In fact, both these torsional modes had partition functions close to those derived from a purely harmonic oscillator model. The greatest combined deviation was $30 \%$, at $2000 \mathrm{~K}$.

A quantum RRK analysis for $k(E)$, referred to as CHEMDIS, ${ }^{28}$ combined with the modified $\beta$ collision analysis of Gilbert et al. ${ }^{29}$ for falloff, was used to predict pressure-dependent rate constants. Table 2 presents three-parameter fits (of the form $\left.B T^{n} \exp (-C / R T)\right)$ of the high-pressure limit rate coefficients for the various pathways.

Figure 8 shows the comparison of the modified Arrhenius fit of the data with the QRRK predicted expression. The deviation between the two expressions is less than $20 \%$ throughout the temperature range investigated (298-2000 K). Figure 8 also shows the QRRK estimated temperature-dependent reaction rate constants for the most significant reactions at atmospheric pressure. The predicted dominant product is at elevated temperatures is trichloroethenol $\left(\mathrm{C}_{2} \mathrm{Cl}_{3} \mathrm{OH}\right)$ by two different paths (directly from $\mathrm{C}^{\bullet} \mathrm{Cl}_{2} \mathrm{CCl}_{2} \mathrm{OH}$ or through TS1). At temperatures approaching $2000 \mathrm{~K}$, the carcinogenic product, trichloracetyl chloride $\left(\mathrm{CCl}_{3} \mathrm{CClO}\right)$, becomes more prominent, along with back reaction to the original reactants.

These predictions are consistent with the work of Kirchner et al., ${ }^{8}$ who made mass spectrometric measurements of the products of $k_{1}$, and confirm their results showing the liberation of the $\mathrm{Cl}$ atom which then attacked the parent molecule. In their work, the dominant product was shown to be $\mathrm{C}_{2} \mathrm{Cl}_{3} \mathrm{OH}$ up to a temperature of $459 \mathrm{~K}$.

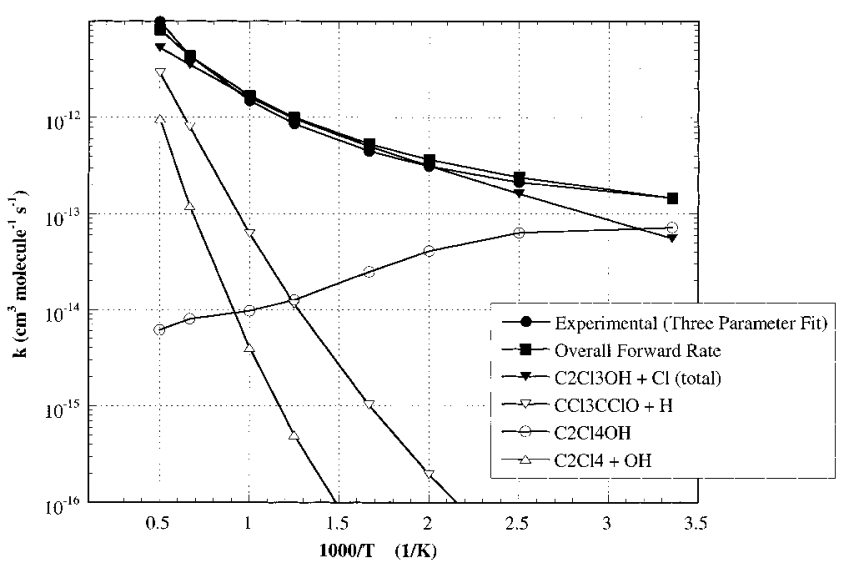

Figure 8. Arrhenius plot of the QRRK model results $(P=1 \mathrm{~atm})$ for the overall forward reaction, the formation of trichloroethenol with $\mathrm{Cl}$ elimination (sum of both paths), the formation of trichloroacetyl chloride with $\mathrm{H}$ elimination, and the forward and reverse paths for $\mathrm{C}_{2} \mathrm{Cl}_{4}+\mathrm{OH}$ $\rightarrow \mathrm{C}^{\cdot} \mathrm{Cl}_{2} \mathrm{CCl}_{2} \mathrm{OH}$. The modified Arrhenius fit to the experimental data has also been included

Though several individual pathways exhibited pressure dependence, the overall forward reaction did not. Figure 9 shows the pressure dependence of the $\mathrm{Cl}$ elimination reaction and the formation of the stabilized activated complex. Chlorine elimination and the formation of the initial stabilized adduct exhibit the expected pressure dependence. Under the conditions of the previous experiments ( $\sim 0.001 \mathrm{~atm}), \mathrm{Cl}$ elimination is the only reaction channel that is important, i.e., all adducts eliminate $\mathrm{Cl}$ atoms. The lack of pressure dependence for the overall forward reaction is once again consistent with the results of Kirchner et al. ${ }^{8}$ They investigated the reaction over a pressure range of $0.5-$ 5.6 mbar with no dependence observed. They discussed that the availability of rapid decomposition paths for the activated complex to products will eliminate pressure dependence, which is confirmed by our analysis.

\section{Conclusions}

New, atmospheric pressure, absolute rate measurements of $k_{1}$ near room temperature verify the results of previous studies. These studies indicated a positive temperature dependence, in contrast to measurements with the other chloroethenes. ${ }^{5-8}$ Additional measurements at higher temperatures indicated a similar trend, with the overall data best fit by a modified Arrhenius expression. Theoretical calculations indicate that this reaction involves a chemically activated system. The observed positive temperature dependence for this addition reaction is due to the presence of a small but distinct barrier $(1.2 \mathrm{kcal} /$ 


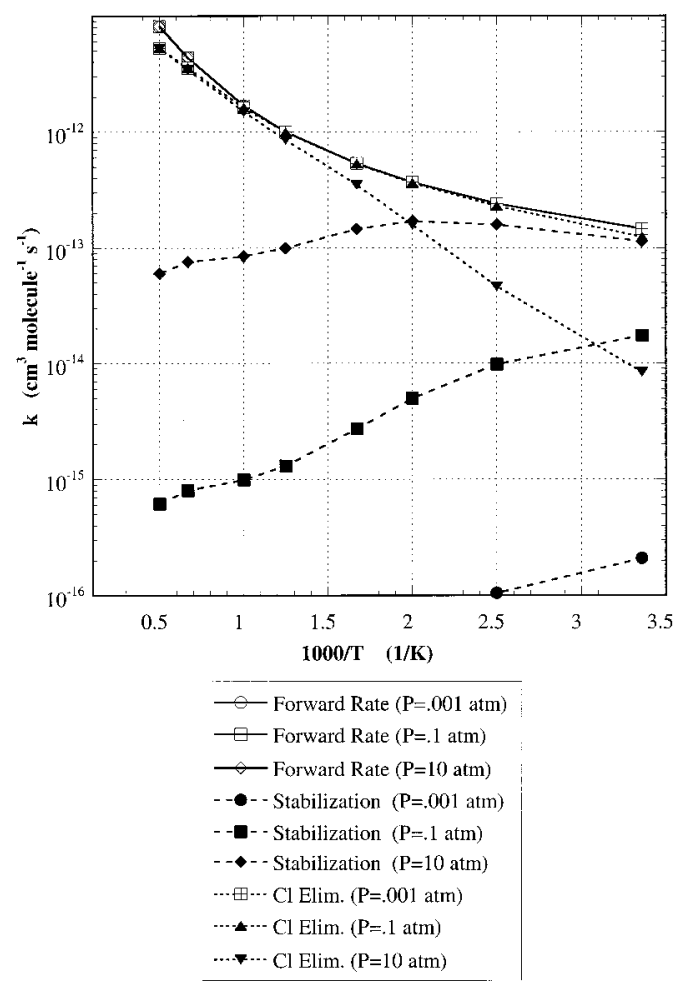

Figure 9. QRRK determined reaction rate constants as a function of pressure and temperature. Included are the overall rate constant (lines) and the individual rate constants for $\mathrm{C}^{\circ} \mathrm{Cl}_{2} \mathrm{CCl}_{2} \mathrm{OH}$ (large dashes) and $\mathrm{C}_{2} \mathrm{Cl}_{3} \mathrm{OH}+\mathrm{Cl}$ (small dashes) at pressures of 0.001, 0.10, and 10.0 atm.

mol) to the initial addition of $\mathrm{OH}$ to the $\mathrm{C}=\mathrm{C}$ double bond. The lack of any observed pressure dependence in previous studies is consistent with this analysis. At room temperature, the dominant reaction channels are adduct stabilization and $\mathrm{Cl}$ elimination yielding trichloroethenol. Our calculations indicate that adduct stabilization accounts for about $50 \%$ of the overall reaction at $1 \mathrm{~atm}$ and $298 \mathrm{~K}$. At higher temperatures encompassing postcombustion conditions, through $1000 \mathrm{~K}, \mathrm{Cl}$ elimination yielding trichloroethenol is the dominant reaction. At even higher temperatures that encompass flame conditions, $\mathrm{H}$ elimination yielding trichloroacetyl chloride becomes more prominent, while the dominant reaction continues to be the formation of trichloroethenol with $\mathrm{Cl}$ elimination. Future efforts will attempt to verify the products and measure the branching ratios to confirm these mechanisms.

\section{Note Added in Proof}

We have reinvestigated this reaction using a boric acid treated injector probe to further minimize surface adsorption behavior. ${ }^{22}$ Under these conditions, surface adsorption for $\mathrm{C}_{2} \mathrm{Cl}_{4}$ concentrations below $10^{15}$ molecules $\mathrm{cm}^{-3}$ was negligible. The second set of measurements and their $2 \sigma$ error limits are consistent with the measurements reported herein and are included in Figure 5, denoted as Tichenor et al. (1999) for comparison.

Acknowledgment. The authors thank Dr. J. W. Bozzelli for his comments during the ab initio calculations and the reaction kinetics analysis, and Dr. R. J. Berry for carrying out the largest energy calculation. All authors acknowledge support from the Environmental Protection Agency (Grant R82-6169-01-0), and P.M. additionally thanks the Robert A. Welch Foundation (Grant B-1174) and the UNT Faculty Research Fund. P.T. and T.Y. also acknowledge a grant of computer time from the Ohio Supercomputer Center (PNS355).

\section{References and Notes}

(1) Gilbert, D.; Goyer, M.; Lyman, W.; Magil, G.; Walker, P.; Wallace, A.; Wechsler, A.; Yee, J. An Exposure and Risk Assessment for Tetrachloroethylene; EPA-440/4-85-015, 1980.

(2) Atkinson, R.; Carter, W. P. L. Chem. Rev. 1984, 84, 437.

(3) Atkinson, R.; Aschmann, S. M.; Goodman, M. A. Int. J. Chem. Kinet. 1987, 19, 299.

(4) Atkinson, R. J. Phys. Chem. Ref. Data, Monogr. 1989, 1.

(5) Howard, C. J. J. Chem. Phys. 1976, 65, 4771.

(6) Davis, D.; Machado, U.; Smith, G.; Wagner, S.; Watson, R. T. Unpublished data cited in Watson, R. T. J. Phys. Chem. Ref. Data 1977, 6 , 871.

(7) Chang, J. S.; Kaufman, F. J. Chem. Phys. 1977, 66, 4989.

(8) Kirchner, K.; Helf, D.; Ott, P.; Vogt, S. Ber. Bunsen-Ges. Phys. Chem. 1990, 94, 77.

(9) Fairchild, P. W.; Smith, G. P.; Crosley, D. R. 19th Symposium (Int.) on Combustion; The Combustion Institute, 1982; p 107.

(10) Warnatz, J.; Bockhorn, H.; Moser, A.; Wenz, H. W. 19th Symposium (Int.) on Combustion; The Combustion Institute, 1982; p 197.

(11) Dean, A. M. J. Phys. Chem. 1985, 89, 4600.

(12) Fang, T. D.; Taylor, P. H.; Dellinger, B. J. Phys. Chem. 1996, 10, 4048.

(13) Fang, T. D.; Taylor, P. H.; Dellinger, B.; Ehlers, C. J.; Berry, R. J. J. Phys. Chem. 1997, 101, 5758.

(14) Fang, T. D.; Taylor, P. H.; Berry, R. J. J. Phys. Chem. A 1999, $103,2700$.

(15) Wollenhaupt, M.; Carl, S. A.; Horowitz, A.; Crowley, J. N. Rate Coefficients for Reaction of $\mathrm{OH}$ with Acetone between 202 and 395 K. $J$. Phys. Chem., submitted.

(16) Demore, W. B.; Goldent, D. M.; Hampson, R. F.; Kurylo, M. J. Howard, C. J.; Ravishankara, A. R.; Kolb, C. E.; Molina, M. J. Chemical Kinetics and Photochemical Data for Use in Stratospheric Modeling, \#12; Jet Propulsion Laboratory Publ. 97-4; National Aeronautics and Space Administration, 1997.

(17) Cox, R. A. J. Photochem. 1974, 3, 175.

(18) Zabel, F. Ber. Bunsen-Ges. Phys. Chem. 1974, 78, 232

(19) Febo, A.; Perrino, C.; Gherardi, M.; Sparapani, R. Environ. Sci. Technol. 1995, 29, 2390.

(20) Graham, J. L.; Dellinger, B.; Swartzbaugh, J. Development of a Photothermal Detoxification Unit, EPA/540/SR-95/526, 1995.

(21) Mallard, W. G. NIST Chemical Kinetics Database 2Q98; NIST Standard Reference Database 17; U. S. Department of Commerce: Gaithersburg, MD, 1998.

(22) Tichenor, L. B.; El-Sinawi, A.; Yamada, T.; Taylor, P. H.; Peng, J.; Hu, X.; Marshall, P. Chemosphere, submitted.

(23) Frisch, M. J.; Trucks, G. W.; Schelgel, H. B.; Gill, P. M. W.; Johnson, B. G.; Robb, M. A.; Cheeseman, J.R.; Keith, T.; Petersson, A.; Montgomery, J. A.; Raghavachari, K.; Al-Laham, M. A.; Zakrzewski, V. G.; Ortiz, J. V.; Foresman, J. B.; Cioslowski, J.; Stefanov, B. B.; Nanayakkara, A.; Challacombe, M.; Peng, C. Y.; Ayala, P. Y.; Chen, W.; Wong, M. W.; Andres, J. L.; Replogle, E. S.; Gomperts, R.; Martin, R. L.; Fox, D. J.; Binkley, J. S.; Defrees, D. J.; Baker, J.; Stewart, J. P.; HeadGordon, M.; Gonzalez, C.; Pople, J. A. Gaussian 94; Gaussian, Inc.: Pittsburgh, PA, 1995

(24) Curtiss, L. A.; Redfern, P. C.; Raghavachari, K.; Rassolov, V.; Pople, J. A. J. Chem. Phys. 1999, 110, 4703.

(25) Curtiss, L. A.; Raghavachari, K.; Redfern, P. C.; Rassolov, V.; Pople, J. A. J. Chem. Phys. 1998, 109, 7764.

(26) Benson, S. W. Thermochemical Kinetics; John Wiley \& Sons: New York, 1976.

(27) Lewis, G. N.; Randall, M.; Pitzer, K. S.; Brewer, L. Thermodynamics; McGraw-Hill: New York, 1961; Chapter 27.

(28) Chang, A. M.; Bozzelli, J. W.; Dean, A. M. In preparation.

(29) Gilbert, R. G.; Luther, K.; Troe, J. Ber. Bunsen-Ges. Phys. Chem. 1983, 87, 169. 